\title{
Solubilized Enzymatic Fuel Cell (SEFC) for Quasi-Continuous Operation Exploiting Carbohydrate Block Copolymer Glyconanoparticle Mediators
}

\author{
5 Jules L. Hammond, ${ }^{\dagger}$ Andrew J. Gross, ${ }^{\dagger}$ A Fabien Giroud, ${ }^{\dagger \odot}$ Christophe Travelet, ${ }^{\dagger}$ Redouane Borsali, ${ }^{*}{ }^{\ddagger}$ \\ 6 and Serge Cosnier ${ }^{*}, \dagger$
}

\author{
7 †Université Grenoble Alpes, CNRS, DCM, 38000 Grenoble, France \\ 8 "Université Grenoble Alpes, CNRS, CERMAV, 38000 Grenoble, France
}

9 S Supporting Information

10 ABSTRACT: Enzymatic biofuel cells are ecofriendly power sources 11 that can deliver $\boldsymbol{\mu W}-\mathrm{mW}$ outputs from renewable substrates, but their 12 stability is a major issue owing to enzyme fragility. The vast majority of 13 reported biofuel cells can only generate power continuously for 14 relatively short periods of time. Here we report a novel "solubilized 15 enzymatic fuel cell (SEFC)” concept for continuous long-term 16 operation. Avoiding surface immobilization techniques allows bio17 catalytic activity to be easily restored or replenished. The biofuel cell 18 exploits freely diffusing enzymes and $\boldsymbol{\beta}$-cyclodextrin-coated glycona19 noparticles with entrapped quinone and thiazoline redox mediators, for 20 mediated glucose and oxygen conversion. The cell was designed with 21 permselective membranes to enable substrate and proton diffusion 22 while trapping the enzymes and glyconanoparticles in separate 23 compartments. The SEFC exhibited a peak power loss of only $26.3 \%$ after 7 days of continuous charge-discharge 24

25
27 nzymatic biofuel cells convert chemical energy into electrical energy by electroenzymatic reactions. ${ }^{1}$ The use of enzymes provides several advantages compared 28 to conventional noble metal catalysts, including very high 29 specificity toward their substrates, high turnover and activity 30 under mild conditions, and the ability to transform complex 31 organic fuels. Enzymes are also biocompatible and environ32 mentally benign, although intrinsically complex and fragile. 33 Another major drawback of enzymes is their limited stability 34 after immobilization on artificial electrode surfaces. Currently 35 there is an urgent need to develop superior strategies to 36 preserve, optimize, and enhance enzyme stability and activity 37 at electrodes for bioelectrocatalysis under various conditions.

38 With state-of-the-art prototype biofuel cells already capable 39 of powering small electronic devices such as pacemakers, 40 lactate sensors, and wireless communication systems for short 41 periods of time, their long-term operational stability remains a 42 crucial parameter for their future success. ${ }^{1-4}$ One of the key 43 factors determining the lifetime of a biofuel cell is the stability 44 of the enzymes and mediators, presenting pivotal concern for 45 their practical application. ${ }^{5}$ Immobilization of the enzyme on 46 the electrode, for example, using carbon nanostructures, ${ }^{6}$ often combined with surface modification chemistry, is considered to 47 be the best way to stabilize the enzyme. However, this method 48 eventually leads to a buildup of inactive enzyme at the surface, 49 making it extremely difficult for the catalytic activity to be 50 restored or replenished. ${ }^{7}$ Enzyme immobilization and entrap- 51 ment methods can also fix the enzymes in inefficient 52 orientations, restricting their degrees of freedom and reducing 53 their activity. Irreversible physical damage to the enzyme upon 54 binding or cross-linking to the electrode is also an issue. Redox 55 mediators are often immobilized together with the enzyme to 56 facilitate electron shuttling to and from the enzyme's active site 57 (mediated electron transfer (MET)). Covalent attachment of 58 the enzyme followed by entrapment of the mediator by cross- 59 linking, encapsulation in polypyrrole films, ${ }^{9}$ or forming a 60 mixed compression with graphite particles ${ }^{2}$ is typically used to 61 stabilize enzymes at electrodes. Such techniques are considered 62 to mitigate catalytic instability and minimize leaching ${ }^{10}$ but at 63 the expense of reduced activity. High concentrations of 64

Received: October 15, 2018

Accepted: December 3, 2018

Published: December 3, 2018 
65 immobilized mediators are typically required to maximize 66 power density, but this can be difficult to realize, expensive, 67 and unsafe due to toxicity, caused by progressive leaching.

68 The aim of this work is to depart from the traditional 69 approach of immobilizing the bioelectrocatalytic components 70 of the fuel cell on the electrodes. Instead, we adopt here a 71 strategy of utilizing enzymes and redox-mediating glyconano72 particles (GNPs) solubilized (i.e., nonimmobilized) in 73 solution. Enzymes and mediators in solution can freely diffuse 74 and rotate for dynamic orientation with each other for effective 75 electron transfer and bioelectrocatalysis. The use of enzymes in 76 solution can also avoid issues related to poor mass transfer ${ }^{11}$ 77 and reproducibility due to complicated enzyme immobilization 78 procedures. $^{12}$ Importantly, Zhu and Zhang ${ }^{13}$ previously 79 demonstrated that higher power densities can be obtained at 80 a nonimmobilized bioanode of a closed biobattery when 81 compared to an immobilized bioanode.

82 If both the enzymes and mediators are solubilized, as 83 explored/reported herein, fresh biocatalysts can be introduced 84 at high concentrations to restore or replenish performance by a 85 simple exchange of the anode and cathode solutions. This will 86 further prolong the biofuel cell lifetime and would address the 87 major problem of conventional biofuel cells whereby the 88 bioelectrodes with immobilized enzymes must be recon89 structed when the enzyme becomes inactive. The concept of 90 refueling the fuel solution of a biofuel cell has been previously 91 demonstrated by Sony Corporation with an immobilized 92 system. However, the cell voltage collapsed to $0.2 \mathrm{~V}$ after 40 93 fuel exchanges (200 min total operation). ${ }^{14}$

94 Taking into account that redox mediators and substrates 95 such as glucose are similar in size, it was not possible to 96 consider a solubilized bioelectrode system that was capable of 97 retaining redox mediators while still permitting diffusion of 98 glucose. In this context, the engineering of redox supra99 molecular entities exhibiting a similar size to proteins is a 100 promising route in the design of bioelectrodes based on a size101 exclusion process. GNP synthesis ${ }^{15}$ not only allows hydro102 phobic and insoluble redox-active species to be solubilized but 103 simultaneously enables size-dependent entrapment within a 104 fuel cell compartment due to their large size via a size-exclusion 105 membrane. Replacing classical redox mediators with redox106 active GNPs opens up the new possibility to separate the 107 anolyte from the catholyte and avoid cross-reaction. Without 108 size exclusion there would be an inevitable drop in open-circuit 109 voltage (OCV), close to zero, due to a mixed potential 110 between the bioanode and biocathode. Furthermore, the use of 111 GNPs can allow the redox-active anolyte/catholyte or fuel to 112 be specifically replenished or restored.

113 In summary, we develop here the use of two types of freely 114 diffusing, solubilized redox glycocopolymer nanoparticles for 115 the electrical wiring of enzymes both at the anode and cathode. 116 Furthermore, we have engineered a new solubilized enzymatic 117 fuel cell (SEFC) device that integrates permselective 118 membranes, allowing us to exploit the size of the GNPs to 119 prevent mediator leaching into the fuel stream or away from 120 their respective anode or cathode compartments.

121 The biofuel cell can be envisaged as the combination of two 122 half-cells that concomitantly undergo oxidation and reduction 123 reactions at the anode and cathode, respectively. Electrons 124 produced by oxidation at the anode flow through the external 125 circuit, delivering power to the load, and are then transferred 126 to the cathode where they participate in the reduction reaction. 127 As it is desirable to utilize abundant and low-cost organic energy sources, we base our system on glucose and oxygen as 128 the fuel and oxidant, respectively. These substrates have 129 attracted considerable attention for implantable and wearable 130 applications, owing to their availability in the body in $\mu \mathrm{M}-\mathrm{mM} 131$ concentrations by human metabolism and consumption, but 132 are equally viable for portable applications. ${ }^{1}$

At the anode, we perform catalytic oxidation of glucose with 134 fungal flavin adenine dinucleotide-dependent glucose dehy- 135 drogenase (FAD-GDH) from Aspergillus sp. using 9,10- 136 phenanthrenequinone (PQ) as the organic redox mediator. 137 PQ was recently shown to be an effective mediator in solution 138 for glucose oxidation with this enzyme compared to other 139 quinone mediators. ${ }^{16}$ For the cathode, we reduce oxygen via a 140 four-electron process to water using the bilirubin oxidase 141 (BOx) enzyme from Myrothecium verrucaria, mediated by bis- 142 pyrene-2,2' -azino-bis(3-ethylbenzothiazoline-6-sulfonic acid) 143 $\left(\mathrm{P}_{2} \mathrm{ABTS}\right){ }^{15}$ In both cases, the mediator is encapsulated 144 within a GNP using a guest-host interaction via $\beta$-cyclodextrin 145 inclusion complexes. The two separate reactions occurring at 146 the anode and cathode are illustrated in Figure 1.

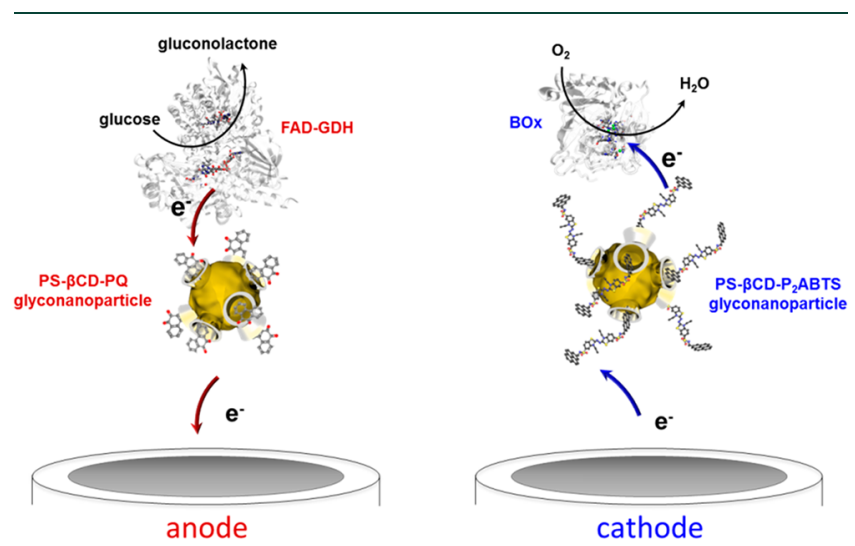

Figure 1. Scheme showing the reactions occurring at the anode (left) and cathode (right)

The redox GNPs were prepared using an amphiphilic $\beta$ - 148 cyclodextrin $(\beta-\mathrm{CD})$ polystyrene diblock copolymer based on 149 a click chemistry reaction. The $\beta$-CD GNPs are obtained by 150 self-assembly with controlled encapsulation of the mediator in 151 a high yield via the nanoprecipitation technique. ${ }^{17}$ Further 152 details of the $\mathrm{P}_{2} \mathrm{ABTS}$ GNP preparation, characterization, and 153 use for catalysis within a cathodic half-cell have been published 154 previously by our group. ${ }^{15}$ To complement the $\mathrm{P}_{2}$ ABTS GNPs 155 and complete the aqueous biofuel cell, new GNPs with 156 entrapped $P Q$ as a redox mediator were developed for the 157 anodic half-cell. We formed PS- $\beta$ CD-PQ GNPs with 158 approximate PQ concentrations of 34.2 and $68.4 \mu \mathrm{M}(1: 1159$ and 1:2, PS- $\beta$ CD:PQ mass). These concentrations are much 160 higher than the maximum concentration achieved when 161 dissolving $\mathrm{PQ}$ in deionized (DI) $\mathrm{H}_{2} \mathrm{O}$ with ultrasonic agitation, 162 of around $5 \mu \mathrm{M}$ [SI, Figure S1]. This demonstrates how 163 increased quantities of a hydrophobic mediator can be 164 incorporated in solution for catalysis via host-guest 165 encapsulation in our GNP system.

TEM imaging (Figure 2) of the PQ GNPs showed $167 \mathrm{fz}$ nanoparticles with average diameters of $20.0 \pm 7.0$ and 43.9168 $\pm 27.7 \mathrm{~nm}$ at 34.2 and $68.4 \mu \mathrm{M}$, respectively. This compares to 169 $43.3 \pm 18.8 \mathrm{~nm}$ for the PS- $\beta$ CD-P ${ }_{2}$ ABTS GNPs (SI, Figure 170 S2). Interestingly, increasing the concentration of the guest 171 altered the average GNP diameter, as shown in the size 172 

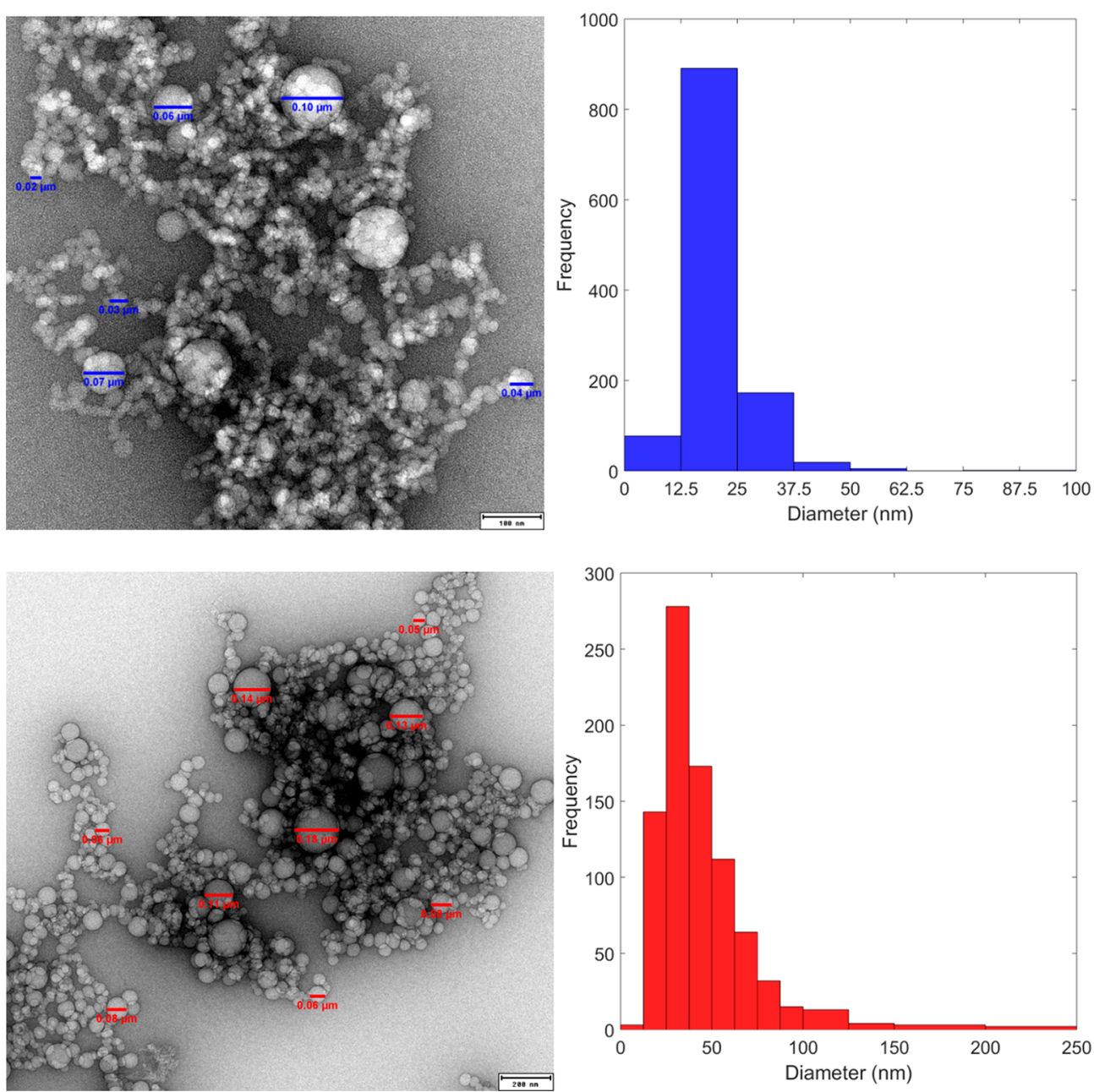

Figure 2. TEM images and histograms showing the typical size distribution of PS- $\beta$ CD-PQ GNPs.
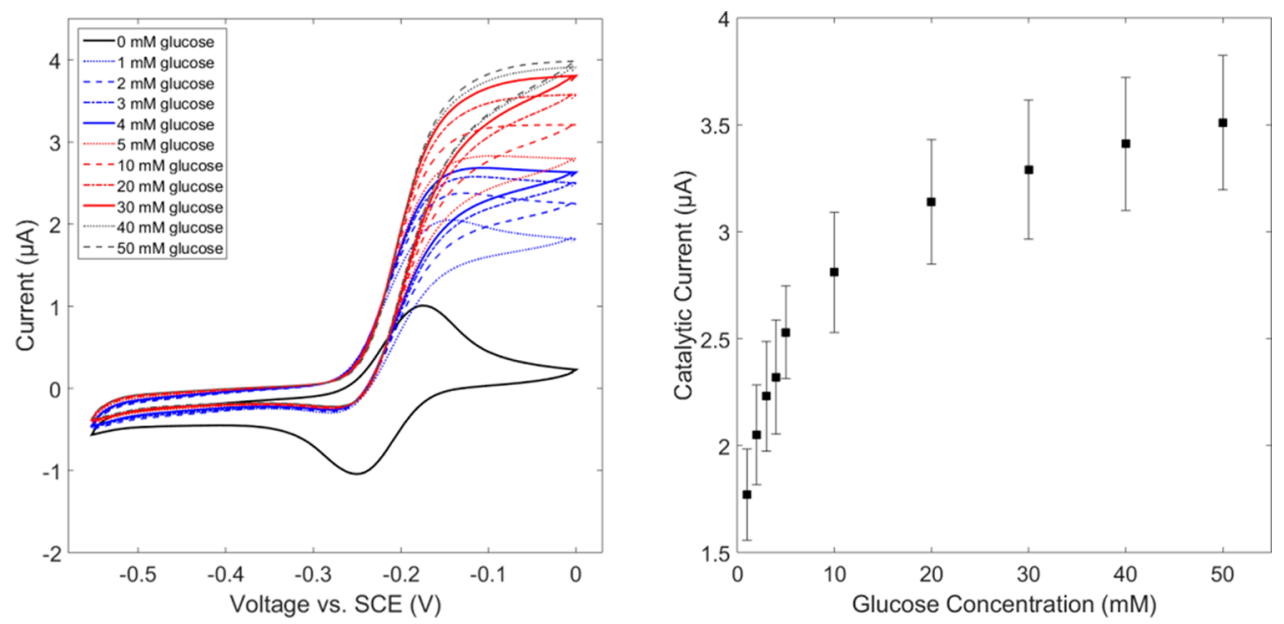

Figure 3. Cyclic voltammograms and glucose dose response for an anode half-cell using GCEs, $2.5 \mathrm{~mL}$ of $34.2 \mu \mathrm{M}$ PS- $\beta$ CD-PQ GNPs, and $0.3 \mathrm{mg}$ of FAD-GDH in $25 \mu \mathrm{L}$ of $\mathrm{pH} 7.0 \mathrm{Mcllvaine}$ buffer, $v=5 \mathrm{mV} \cdot \mathrm{s}^{-1}$.

173 distributions (Figure 2), with this tendency also supported by 174 the results of dynamic light scattering (DLS) experiments (SI, 175 Figure S3 and Table S1). Importantly, the electroactivity of the 176 PS- $\beta$ CD-PQ GNPs is approximately doubled (1:1.91) when 177 doubling the concentration of the mediator, as demonstrated 178 by the scan-rate dependence shown on cyclic voltammograms 179 (SI, Figures S4a,b and Table S2).
TEM images showed no change in the GNPs after 2 months 180 or after addition of $\mathrm{pH} 7.0$ McIlvaine buffer (data not shown). 181 This is consistent with the apparent stability previously 182 observed for our PS- $\beta$ CD-P 2 ABTS GNPs. ${ }^{15}$ The electro- 183 catalytic activity of the new PQ GNPs was then confirmed at 184 glassy carbon electrodes (GCEs) with increasing concen- 185 trations of glucose in $\mathrm{DI} \mathrm{H}_{2} \mathrm{O}$ (Figure 3). Furthermore, system $186 \mathrm{f3}$ 

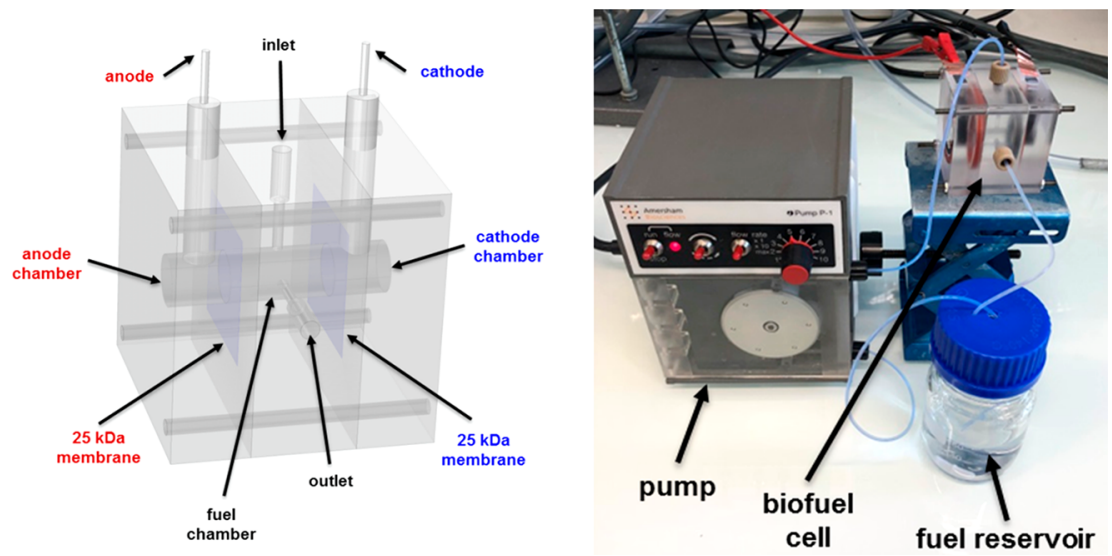

Figure 4. 3D annotated drawing (left) showing the fuel cell components and photograph (right) of the setup when connected.

187 performance was found to be limited by the enzyme mass ( 120 $188 \mu \mathrm{g} \cdot \mathrm{mL}^{-1}$ ) in the system (SI, Figure S5). At the higher bound of 189 a typical blood glucose level $(5 \mathrm{mM})$, the catalytic current was 190 around $2.5 \pm 0.2 \mu \mathrm{A}$.

191 A new fuel cell (Figure 4) was developed specifically for our 192 system and consists of three main parts. The central chamber $193(V=1.5 \mathrm{~mL})$ is connected to a peristaltic pump to provide a 194 constant flow of fuel to the adjacent compartments $(V=1 \mathrm{~mL})$ 195 that contain the anode and cathode biocatalytic components. 196 To prevent loss of the enzymes and mediators from their 197 respective compartments, dialysis membranes with a cutoff 198 value of $25 \mathrm{kDa}$ are used as separators and sealed with a double 199 O-ring system. This cutoff value translates to an approximate $200 R_{\min }$ of $1.9 \mathrm{~nm}\left(D_{\min }=3.9 \mathrm{~nm}\right)$, calculated using the following 201 equation, ${ }^{18} R_{\min }=0.066(D a)^{1 / 3}$, and the cutoff value is 202 sufficiently smaller than the diameter of PQ $(20.0 \pm 7.0$ and $20343.9 \pm 27.7 \mathrm{~nm}$ at 34 and $68 \mu \mathrm{M}$, respectively) and $\mathrm{P}_{2} \mathrm{ABTS}$ $204(43.3 \mathrm{~nm} \pm 18.8 \mathrm{~nm})$ GNPs and the enzymes $(\mathrm{BOx}=66-68$ $205 \mathrm{kDa}$ and FAD-GDH $=95-135 \mathrm{kDa})$. Carbon nanotube 206 buckypaper offers properties such as high specific surface area, 207 mechanical flexibility, and high electrical conductivity. ${ }^{19}$ To 208 increase power output, electrodes with increased area $(5 \times 40$ $209 \mathrm{~mm}$ ) were fabricated by attaching commercial carbon 210 nanotube buckypaper to graphite foil current collectors using 211 carbon paste. To limit evaporation and secure the electrodes in 212 place, the compartments were sealed with tape and then the 213 electrodes terminated with conductive adhesive copper tape. 214 A peristaltic pump operating at a flow rate of $80 \mu \mathrm{L} \cdot \mathrm{min}^{-1}$ 215 (mimicking typical blood vessel flow ${ }^{20}$ ) was used to deliver a 216 continuous stream of $\mathrm{pH} 7.0$ Mcllvaine buffer containing 217 ambient $\mathrm{O}_{2}$ and $5 \mathrm{mM}$ glucose from a $50 \mathrm{~mL}$ reservoir. A 218 volume of $800 \mu \mathrm{L}$ of PQ GNPs with $120 \mu \mathrm{g}$ of FAD-GDH and $219800 \mu \mathrm{L}$ of $\mathrm{P}_{2} \mathrm{ABTS}$ GNPs with $200 \mu \mathrm{g}$ of BOx were injected 220 into the anode and cathode compartments, respectively.

221 The electrocatalytic behavior of the bioelectrodes was 222 verified for both half-cells (SI, Figures S6 and S7). Here we 223 can compare the catalytic performance with our previous work 224 on buckypaper electrodes ${ }^{19}$ with immobilized enzyme and 225 mediator bioelectrodes (see the SI for further details). Using a 226 similar but not identical quinone mediator and FAD-GDH 227 enzyme, we produced a catalytic output of $0.637 \mathrm{~mA} . \mathrm{cm}^{-2}$. $228 \mathrm{mg}^{-1}$. In contrast, the solubilized system with PQ GNPs and $229 \mathrm{FAD}-\mathrm{GDH}$ reported here achieved $2.05 \mathrm{~mA} \cdot \mathrm{cm}^{-2} \cdot \mathrm{mg}^{-1}$. 230 Likewise, for the biocathode, prepared with immobilized $231 \mathrm{BOx}$, we achieved $1.77 \mathrm{~mA} \cdot \mathrm{cm}^{-2} \cdot \mathrm{mg}^{-1}$. This compares to a 232 catalytic output of $3.79 \mathrm{~mA} \cdot \mathrm{cm}^{-2} \cdot \mathrm{mg}^{-1}$ for the solubilized BOx system obtained in this work. We therefore clearly observe 233 better catalytic performances per amount of enzyme catalyst in 234 this work compared to state-of-the-art buckypaper anodes and 235 cathodes with immobilized enzymes.

236

Polarization plots (Figure 5) were performed for the biofuel $237 \mathrm{fs}$ cell by increasing the discharge current and recording the cell 238

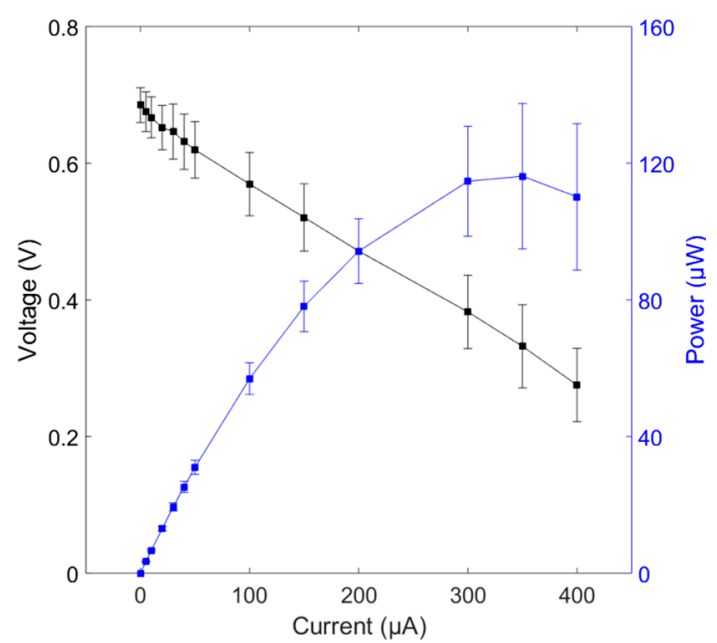

Figure 5. Cell performance $(n=3)$ showing voltage (black, left axis) and power (blue, right axis) as a function of current at a fuel flow rate of $80 \mu \mathrm{L} \cdot \mathrm{min}^{-1}(\mathrm{pH} 7.0$ McIlvaine buffer with $5 \mathrm{mM}$ glucose and ambient $\mathrm{O}_{2}$ ), with $120 \mu \mathrm{g}$ of FAD-GDH, $200 \mu \mathrm{g}$ of $\mathrm{BOx}$, and $800 \mu \mathrm{L}$ of each GNP suspension.

voltage after $30 \mathrm{~s}$. A maximum power point of $116.2 \pm 21.3239$ $\mu \mathrm{W}$ was observed at a discharge current of $350 \mu \mathrm{A}$. The 240 observed OCV of the fuel cell was $0.685 \mathrm{~V} \pm 26 \mathrm{mV}$. 241

Operational stability of the fuel cell was tested by performing 242 constant charge-discharge cycling for extended periods. The 243 cell is discharged at a current of $50 \mu \mathrm{A}$ until it reaches $0.25 \mathrm{~V} 244$ and then is allowed to recover until the voltage reaches $0.65 \mathrm{~V} .245$ The glucose oxidation and oxygen reduction reactions are 246 continuous. The selected current and voltage values provide a 247 compromise between charge/discharge times, maximizing the 248 duty cycle of power generation while also preventing damage 249 to the enzyme. It is important to note that many previous 250 reports of biofuel cell stability operate the device periodically 251 for relatively short periods of time.

A typical charge-discharge profile is shown in Figure 6a,b. $253 \mathrm{fo}$ The charge and discharge times were then calculated at 254 

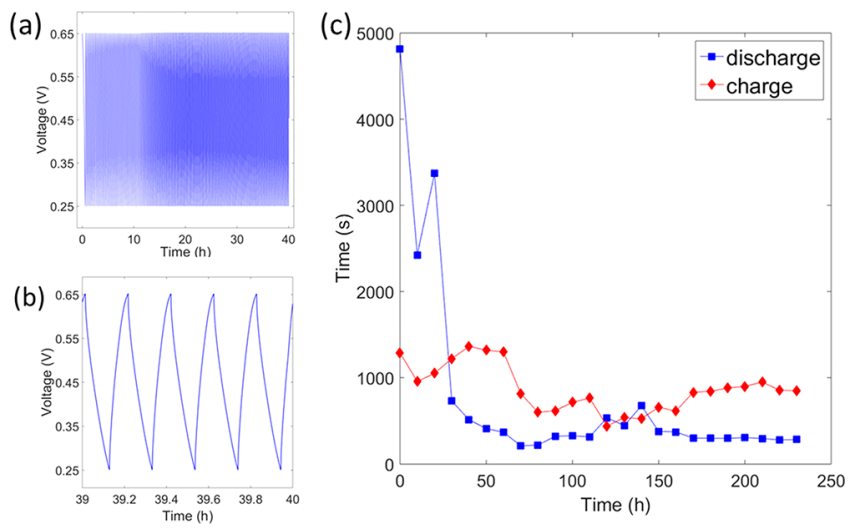

Figure 6. Typical charge-discharge cycles (a), zoomed period

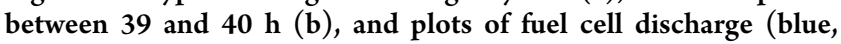
square marker) and charge (red, diamond marker) stability at $10 \mathrm{~h}$ intervals (c), all at a $50 \mu \mathrm{A}$ discharge current and fuel flow rate of $80 \mu \mathrm{L} \cdot \mathrm{min}^{-1}$ ( $\mathrm{pH} 7.0 \mathrm{McIlvaine}$ buffer with $5 \mathrm{mM}$ glucose and ambient $\mathrm{O}_{2}$ ) with $120 \mu \mathrm{g}$ of FAD-GDH, $200 \mu \mathrm{g}$ of $\mathrm{BOx}$, and 800 $\mu \mathrm{L}$ of each GNP suspension.

255 intervals of $10 \mathrm{~h}$ and showed a stabilization of the discharge 256 time after about $30 \mathrm{~h}$ (Figure 6c). After 10 days, the fuel cell 257 still provided discharge times of around $5 \mathrm{~min}$ with charge 258 times of around $15 \mathrm{~min}$.

259 To provide a further indicator of the fuel cell stability, 260 discharge tests at the peak discharge current $(350 \mu \mathrm{A})$ were 261 conducted at 2 and 7 days (typical discharge profiles shown in 262 SI, Figure S8). This was to provide a further indicator for 263 degradation of the fuel cell. After 2 days, the mean power was $264115.3 \pm 24.7 \mu \mathrm{W}(n=3)$, which is similar to the values 265 obtained during initial characterization of the maximum power 266 point during evaluation of the polarization profiles. At 7 days, 267 the mean power dropped to $84.9 \pm 2.9 \mu \mathrm{W}(n=5)$, equating 268 to a power loss of $26.3 \%$. As a comparison, a power loss of $65 \%$ 269 was reported by Zhu and Zhang after operating the fuel cell for 270 just 6 rounds of $2 \mathrm{~h}$ across a period of 12 days.

271 Furthermore, one fuel cell that was already subjected to 7 272 days of operational cycling at a discharge current of $50 \mu \mathrm{A}$ was 273 cycled at a higher discharge current of $350 \mu \mathrm{A}$ for $24 \mathrm{~h}$ (SI,
Figures S9-S11). This fuel cell provided relatively stable 274 operational performance with discharge time falling from 20 to 275 $15 \mathrm{~s}(-25 \%)$ and charge time increasing from 158 to $340 \mathrm{~s} 276$ $(+115 \%)$. This demonstrates the ability to operate the biofuel 277 cell at higher discharge currents over long periods of time 278 while retaining a reasonable level of charge-discharge time 279 stability.

The recirculating fuel solution was tested for the presence of 281 any enzymes and mediators after completion of the operational 282 stability tests and showed no evidence for catalysis (black 283 lines), as shown by the control experiments (red/blue lines for 284 anode/cathode, respectively; Figure 7a,b). This confirms that $285 \mathrm{f} 7$ the biocatalytic elements are retained in their respective 286 chambers and do not leach into the fuel stream. This is a 287 testament to the GNPs, which, owing to their markedly larger 288 sizes compared to classical redox mediators, provide the ability 289 to constrain them within the anode and cathode compartments 290 while allowing diffusion of the substrates, glucose, and oxygen. 291 It is emphasized that redox mediators without nanoparticle 292 encapsulation would not be retained owing to their smaller 293 molecular size. A control experiment using classical redox 294 mediators in place of the GNPs is described further below. 295

To check for the presence of adsorbed biocatalytic 296 components, discharge profiles were performed following 7297 days of operational cycling at $50 \mu \mathrm{A}$ and after using different 298 rinse techniques (SI, Figures S12 and S13). Although an OCV 299 develops (after resting the cell for $2 \mathrm{~h}$ between each rinse), 300 there is negligible power generated and no operational cycling 301 can be performed, ruling out significant adsorption of the 302 biocatalysts. The presence of only trace quantities of 303 biocatalytic components is particularly attractive as the cell 304 chambers can be effectively refreshed.

Finally, a control experiment without PS- $\beta$ CD GNPs to 306 encapsulate the mediators but instead with solubilized 307 mediators was carried out. This control test confirmed that 308 the addition of GNPs in the system helps to efficiently stabilize 309 and improve performance. Without the GNPs, the perform- 310 ance was lower and rapidly degraded, with the charge times 311 steadily increasing to the point that the cell failed to recharge 312 after $20 \mathrm{~h}$ (SI, Figures S14 and S15). This was most likely 313
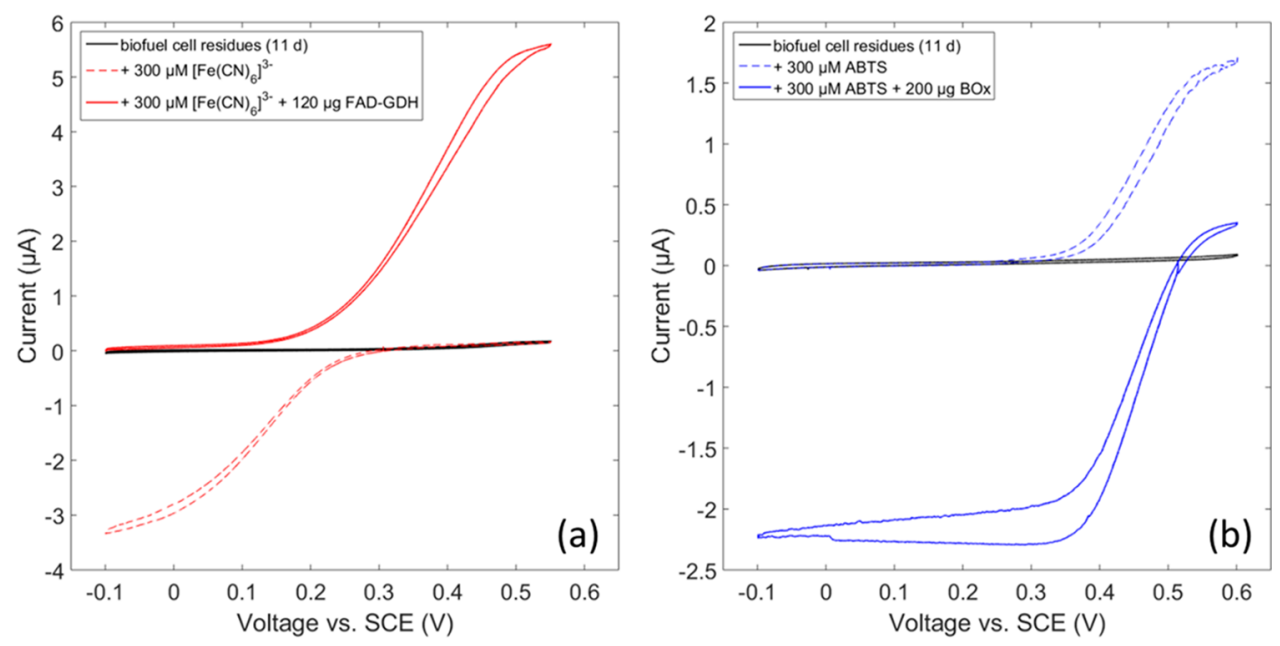

Figure 7. CVs showing response at GCEs for biofuel cell residues (black) with (a) $+300 \mu \mathrm{M}\left[\mathrm{Fe}(\mathrm{CN})_{6}\right]^{3-}($ red, dashed) and $+120 \mu \mathrm{g}$ of FADGDH (red), all in saturated Ar with an Ar blanket, $2 \mathrm{mV} \cdot \mathrm{s}^{-1}$, and (b) $+300 \mu \mathrm{M}$ ABTS (blue, dashed) and $+200 \mu \mathrm{g}$ of BOx (blue), all in saturated $\mathrm{O}_{2}$ with an $\mathrm{O}_{2}$ blanket, $2 \mathrm{mV} \cdot \mathrm{s}^{-1}$. 
314 caused by the mediators readily leaching into the fuel flow and 315 their concentration slowly diminishing.

316 To conclude, we demonstrated an enzymatic biofuel cell 317 whereby the biocatalytic components are in the aqueous phase 318 and therefore able to freely diffuse, shifting from the classical 319 use of immobilized enzymes and mediators. With the use of 320 GNPs made from the self-assembly of a carbohydrate-based 321 block copolymer ( $\beta$-cyclodextrin- $b$-PS), including new GNPs 322 prepared with phenanthrenequinone, we show how increased 323 quantities of mediator can be incorporated into the system to 324 increase catalytic current. With the integration of carbon 325 nanotube buckypaper electrodes into the diffusion-based 326 biofuel cell, currents were enhanced by a factor of around 32785 , relative to GCEs. We have also shown that this novel fuel 328 cell design significantly extends the operational lifetime, for 329 example, by preventing leaching of the mediator through a 330 permselective membrane. After 7 days of operation, the peak 331 power of the optimized biofuel cell only dropped by $26 \%$ to $33284.9 \mu \mathrm{W}$. Further, we clearly show evidence that the use of 333 enzymes in solution can be a viable approach in biofuel cell 334 design, contrary to the general consensus in the literature. A 335 further advantage of this diffusion-based biofuel cell, to be 336 explored in the future, is the possibility to easily recycle and 337 refresh the biocatalytic components. It is feasible that SEFCs, 338 alongside a boost converter, could be used as a green power 339 source for powering low-power portable lab-on-a-chip 340 electronics to perform functions such as quasi-continuous 341 monitoring with data transmission.

\section{ASSOCIATED CONTENT 343 S Supporting Information}

344 The Supporting Information is available free of charge on the 345 ACS Publications website at DOI: 10.1021/acsenergy346 lett.8b01972.

347 Full details of reagents, materials, and experimental 348 methods, further optical, electrochemical, and electronic 349 characterization, results from control tests, as well as 350 calculations comparing systems with immobilized versus $351 \quad$ solubilized biocatalysts (PDF)

\section{$352 \square$ AUTHOR INFORMATION}

\section{Corresponding Authors}

354 *E-mail: redouane.borsali@univ-grenoble-alpes.fr (R.B.). 355 *E-mail: serge.cosnier@univ-grenoble-alpes.fr (S.C.).

356 ORCID $\odot$

357 Jules L. Hammond: 0000-0002-3308-5421

358 Andrew J. Gross: 0000-0002-7356-7089

359 Fabien Giroud: 0000-0001-6611-2687

360 Notes

361 The authors declare no competing financial interest.

\section{$362 \square$ ACKNOWLEDGMENTS}

363 We gratefully acknowledge the financial support of LabEx 364 ARCANE (ANR-11LABX-0003-01) and the Institut Carnot 365 PolyNat (CARN 0007-01) for postdoctoral funding. We also 366 acknowledge the support of the ICMG Chemistry Nanobio 367 Platform for providing facilities (PCN-ICMG).

\section{$368 \square$ REFERENCES}

369 (1) Cosnier, S.; Gross, A. J.; Le Goff, A.; Holzinger, M. Recent 370 Advances on Enzymatic Glucose/Oxygen and Hydrogen/Oxygen
Biofuel Cells: Achievements and Limitations. J. Power Sources 2016, 371 325, 252-263.

(2) Cinquin, P.; Gondran, C.; Giroud, F.; Mazabrard, S.; Pellissier, 373 A.; Boucher, F.; Alcaraz, J.-P.; Gorgy, K.; Lenouvel, F.; Mathé, S.; 374 et al. A Glucose BioFuel Cell Implanted in Rats. PLoS One 2010, 5375 (5), No. e10476.

(3) MacVittie, K.; Halamek, J.; Halámková, L.; Southcott, M.; 377 Jemison, W. D.; Lobel, R.; Katz, E. From "Cyborg" Lobsters to a 378 Pacemaker Powered by Implantable Biofuel Cells. Energy Environ. Sci. 379 2013, 6, 81-86.

380

(4) Monsalve, K.; Mazurenko, I.; Lalaoui, N.; Le Goff, A.; Holzinger, 381 M.; Infossi, P.; Nitsche, S.; Lojou, J. Y.; Giudici-Orticoni, M. T.; 382 Cosnier, S.; et al. A $\mathrm{H}_{2} / \mathrm{O}_{2}$ Enzymatic Fuel Cell as a Sustainable 383 Power for a Wireless Device. Electrochem. Commun. 2015, 60, 216- 384 220.

(5) Moehlenbrock, M. J.; Minteer, S. D. Extended Lifetime Biofuel 386 Cells. Chem. Soc. Rev. 2008, 37 (6), 1188.

(6) Mazurenko, I.; Monsalve, K.; Infossi, P.; Giudici-Orticoni, M.-T.; 388 Topin, F.; Mano, N.; Lojou, E. Impact of Substrate Diffusion and 389 Enzyme Distribution in 3D-Porous Electrodes: A Combined Electro- 390 chemical and Modelling Study of a Thermostable $\mathrm{H}_{2} / \mathrm{O}_{2}$ Enzymatic 391 Fuel Cell. Energy Environ. Sci. 2017, 10 (9), 1966-1982. 392

(7) Rubenwolf, S.; Kerzenmacher, S.; Zengerle, R.; von Stetten, F. 393 Strategies to Extend the Lifetime of Bioelectrochemical Enzyme 394 Electrodes for Biosensing and Biofuel Cell Applications. Appl. 395 Microbiol. Biotechnol. 2011, 89 (5), 1315-1322.

(8) Merle, G.; Habrioux, A.; Servat, K.; Rolland, M.; Innocent, C.; 397 Kokoh, K. B.; Tingry, S. Long-Term Activity of Covalent Grafted 398 Biocatalysts during Intermittent Use of a Glucose/ $\mathrm{O}_{2}$ Biofuel Cell. 399 Electrochim. Acta 2009, 54 (11), 2998-3003.

400

(9) Kim, J.; Kim, S. I.; Yoo, K.-H. Polypyrrole Nanowire-Based 401 Enzymatic Biofuel Cells. Biosens. Bioelectron. 2009, 25 (2), 350-355. 402

(10) Schuhmann, W.; Wohlschläger, H.; Lammert, R.; Schmidt, H. 403 L.; Löffler, U.; Wiemhöfer, H. D.; Göpel, W. Leaching of 404 Dimethylferrocene, a Redox Mediator in Amperometric Enzyme 405 Electrodes. Sens. Actuators, B 1990, 1 (1-6), 571-575. 406

(11) Johnston, W.; Maynard, N.; Liaw, B. Y.; Cooney, M. J. In Situ 407 Measurement of Activity and Mass Transfer Effects in Enzyme 408 Immobilized Electrodes. Enzyme Microb. Technol. 2006, 39 (1), 131- 409 140.

(12) Zhao, X.; Jia, H.; Kim, J.; Wang, P. Kinetic Limitations of a 411 Bioelectrochemical Electrode Using Carbon Nanotube-Attached 412 Glucose Oxidase for Biofuel Cells. Biotechnol. Bioeng. 2009, 104413 (6), 1068-1074.

414

(13) Zhu, Z.; Zhang, Y.-H. P. Use of Nonimmobilized Enzymes and 415 Mediators Achieved High Power Densities in Closed Biobatteries. 416 Energy Sci. Eng. 2015, 3 (5), 490-497.

417

(14) Fujita, S.; Yamanoi, S.; Murata, K.; Mita, H.; Samukawa, T.; 418 Nakagawa, T.; Sakai, H.; Tokita, Y. A Repeatedly Refuelable Mediated 419 Biofuel Cell Based on a Hierarchical Porous Carbon Electrode. Sci. 420 Rep. 2015, 4 (1), 4937.

(15) Gross, A. J.; Chen, X.; Giroud, F.; Travelet, C.; Borsali, R.; 422 Cosnier, S. Redox-Active Glyconanoparticles as Electron Shuttles for 423 Mediated Electron Transfer with Bilirubin Oxidase in Solution. J. Am. 424 Chem. Soc. 2017, 139 (45), 16076-16079.

(16) Tsuruoka, N.; Sadakane, T.; Hayashi, R.; Tsujimura, S. 426 Bimolecular Rate Constants for FAD-Dependent Glucose Dehydro- 427 genase from Aspergillus Terreus and Organic Electron Acceptors. Int. J. 428 Mol. Sci. 2017, 18 (3), 604.

(17) Gross, A. J.; Haddad, R.; Travelet, C.; Reynaud, E.; Audebert, 430 P.; Borsali, R.; Cosnier, S. Redox-Active Carbohydrate-Coated 431 Nanoparticles: Self-Assembly of a Cyclodextrin-Polystyrene Glyco- 432 polymer with Tetrazine-Naphthalimide. Langmuir 2016, 32 (45), 433 11939-11945.

(18) Erickson, H. P. Size and Shape of Protein Molecules at the 435 Nanometer Level Determined by Sedimentation, Gel Filtration, and 436 Electron Microscopy. Biol. Proced. Online 2009, 11 (1), 32-51. 437

(19) Gross, A. J.; Chen, X.; Giroud, F.; Abreu, C.; Le Goff, A.; 438 Holzinger, M.; Cosnier, S. A High Power Buckypaper Biofuel Cell: 439 
440 Exploiting 1,10-Phenanthroline-5,6-Dione with FAD-Dependent 441 Dehydrogenase for Catalytically-Powerful Glucose Oxidation. ACS 442 Catal. 2017, 7 (7), 4408-4416.

443 (20) Wang, Y.; Lu, A.; Gil-Flamer, J.; Tan, O.; Izatt, J. A.; Huang, D. 444 Measurement of Total Blood Flow in the Normal Human Retina 445 Using Doppler Fourier-Domain Optical Coherence Tomography. Br. 446 J. Ophthalmol. 2009, 93 (5), 634-637. 